\title{
The quality of life of children with attention deficit/hyperactivity disorder: a systematic review
}

\author{
Marina Danckaerts · Edmund J. S. Sonuga-Barke · Tobias Banaschewski · Jan Buitelaar • \\ Manfred Döpfner · Chris Hollis · Paramala Santosh · Aribert Rothenberger · Joseph Sergeant · \\ Hans-Christoph Steinhausen · Eric Taylor · Alessandro Zuddas · David Coghill
}

Received: 28 October 2008/Accepted: 8 July 2009/Published online: 26 July 2009

(c) Springer-Verlag 2009

\begin{abstract}
Quality of life (QoL) describes an individual's subjective perception of their position in life as evidenced by their physical, psychological, and social functioning. QoL has become an increasingly important measure of outcome in child mental health clinical work and research. Here we provide a systematic review of QoL studies in children and young people with attention deficit hyperactivity disorder (ADHD) and address three main questions. (1) What is the impact of ADHD on QoL? (2) What are the
\end{abstract}

\section{Danckaerts}

Department of Child and Adolescent Psychiatry,

University Hospitals Leuven, Leuven, Belgium

\section{E. J. S. Sonuga-Barke}

School of Psychology, University of Southampton,

Southampton, UK

E. J. S. Sonuga-Barke · E. Taylor

Social, Genetic, Developmental Psychiatry Centre,

Institute of Psychiatry, London, UK

E. J. S. Sonuga-Barke

Child Study Center, New York University, New York, USA

E. J. S. Sonuga-Barke

Department of Experimental Clinical and Health Psychology,

University of Gent, Ghent, Belgium

T. Banaschewski

Department of Child and Adolescent Psychiatry

and Psychotherapy, Central Institute of Mental Health,

University of Heidelberg, Mannheim, Germany

J. Buitelaar

Department of Psychiatry, Radboud University Nijmegen

Medical Center, Nijmegen, Netherlands

M. Döpfner

University of Cologne, Cologne, Germany relationships between ADHD symptoms, functional impairment and the mediators and moderators of QoL in ADHD? (3) Does the treatment of ADHD impact on QoL? Databases were systematically searched to identify research studies describing QoL in ADHD. Thirty six relevant articles were identified. Robust negative effects on QoL are reported by the parents of children with ADHD across a broad range of psycho-social, achievement and self evaluation domains. Children with ADHD rate their

\author{
C. Hollis \\ University of Nottingham, Nottingham, UK \\ P. Santosh \\ Great Ormond Street Hospital, London, UK \\ A. Rothenberger \\ University of Goettingen, Goettingen, Germany \\ J. Sergeant \\ Free University, Amsterdam, The Netherlands \\ H.-C. Steinhausen \\ University of Zurich, Zurich, Switzerland
}

\author{
A. Zuddas \\ Cagliari University, Cagliari, Italy \\ D. Coghill $(\bowtie)$ \\ Centre for Neuroscience, Division of Medicine, \\ University of Dundee, 19 Dudhope Terrace, \\ Dundee DD3 6HH, UK \\ e-mail: d.r.coghill@dundee.ac.uk
}


own QoL less negatively than their parents and do not always seeing themselves as functioning less well than healthy controls. ADHD has a comparable overall impact on QoL compared to other mental health conditions and severe physical disorders. Increased symptom level and impairment predicts poorer QoL. The presence of comorbid conditions or psychosocial stressors helps explain these effects. There is emerging evidence that QoL improves with effective treatment. In conclusion, ADHD seriously compromises QoL especially when seen from a parents' perspective. QoL outcomes should be included as a matter of course in future treatment studies.

Keywords Attention deficit/hyperactivity disorder (ADHD) - Quality of life · Systematic review

\section{Introduction}

As medicine has moved on from a "life preserving" to a "health promoting" science [95], the concept of Quality of Life (QoL) has become increasingly important in the study of medical conditions, their impact and their outcome [18]. The QoL concept has been defined in many ways, but all definitions, to a greater or lesser extent, emphasize the ideal state as one of general well-being in which an individual's day-to-day functioning, across a wide range of domains, is unencumbered by the potentially adverse impact of disease or disorder. Leidy et al. [44] defined QoL as "an individual's subjective perception of the impact of health status, including disease and treatment, on physical, psychological, and social functioning." This is compatible with the WHO QoL group's description of QoL as "the individuals perception of their position in life, in the context of culture and value systems in which they live, and in relation to their goals, expectations, standards and concerns" [91]. Almost all QoL definitions and measures include physical, social and psychological domains (although similar domains are often labelled differently). A cognitive domain is also commonly included [24]. Although QoL is influenced by many proximal (i.e., family, friendship) and distal (socioeconomic and cultural) forces, illness is one of the most potent influences [24]. In addition to the effects of physical illness on QoL, there is now substantial evidence that mental illness has major impact [7, 50, 70].

A comprehensive discussion of the issues relating to the QoL concept in child and adolescent mental health is beyond the scope of the current review but can be found in a recent paper by the authors [18]. However, a number of key conceptual and measurement are discussed below.

Both the DSM-IV-TR [1] and ICD-10 [96] diagnostic systems emphasize the importance of there being both symptoms and impairment before a diagnosis of mental disorder can be made. However, the distinctions between symptoms and their associated functional impairments are often not as clear and one would wish and their relationships with QoL, remain under-specified. For example some QoL items, designed for patients with physical illness, tap psychiatric symptoms (e.g. "how often did your child feel really sad?") or the types of impairment commonly associated with psychiatric disorders (e.g. "how often did he/ she finish all of his/her homework?"). As a consequence there is significant potential for overlap between instruments designed to measure QoL and those used to measure either symptomatology or impairment. It is therefore vital that, as far as possible, we draw clear distinctions between symptoms (e.g., low mood or poor concentration) and their potential effects (i.e., functional impairment and reduced QoL) and then also between impairment on the one hand and QoL on the other. Otherwise there is a clear risk that apparent QoL effects are so closely related to symptoms and impairment that their association with the disorder will become a tautology.

Also the concept of "validity" of QoL instruments has been particularly difficult to define and measure due to the lack of an agreed and objective gold standard of QoL. Current approaches suggest the employment of quantitative (e.g. factor analysis) and qualitative (e.g. patient debriefing questionnaires and patient panels) techniques. While these procedures have been increasingly used in the development of instruments to measure QoL in children and young people the process has not yet been repeated in different patient groups. And in particular there has been little work conducted to demonstrate validity in children with mental health problems.

Another consideration concerns the usefulness of both generic and disorder-specific measures of QoL and the relationships between these two very different types of measure. Generic measures are designed to be more comprehensive in their coverage, but may as a consequence be less sensitive to treatment-related change. Disorder-specific measures, or modules, focus in on areas of particular concern in relation to a specific disorder and may therefore be more sensitive to treatment effects but do readily not allow comparison with other disorders.

While it is generally accepted that QoL is a multidimensional concept and that the core domains tap into physical, psychological, cognitive and social aspects of functioning it is still the case that different QoL measures define these domains in different ways and then go on to divide them up into different sub-domains. As a consequence there is a considerable degree of inter-instrument non-overlap and we cannot simply assume equal coverage by different measures or that all generic QoL measures cover the necessary ground. This often makes it difficult to 
make direct comparisons between studies that have employed different instruments.

QoL is seen primarily as a patient-reported outcome [48, 79] with a key distinction being between independent assessment (e.g., he/she cannot concentrate and this stops him or her functioning at school and I think he/she should feel bad about this) and the "subjective" appraisal (I cannot concentrate, this stops me working at school and I feel badly about this and it impacts generally on how I feel about myself). In this respect a child's own report seems essential to accurately capture their QoL. However, this is complicated by several issues. Young children (e.g., before the age of 7 or 8 years of age) may lack the understanding, insight or communication skills to provide valid self ratings [10]. This may be accentuated in the case of; children with learning disabilities; those for whom mental health conditions impact on their ability to reflect and report upon their internal state accurately (e.g., depression); or as is often the case with ADHD, where the child is unable to concentrate and apply themselves to answering a questionnaire. In these cases one may have to rely on a proxy rating by a parent or a carer. As a consequence measures of QoL designed for child populations usually have both a child and parent completed versions. Clearly a proxy rating will allow only a partial sense of the overall impact of the condition on QoL which may place important constraints on the validity of studies that do not directly ask the child about their QoL. It is also important to note that the levels of agreement between child and other informants are modest [39], especially with regard to the non-observable aspects of QoL. Parent/carer ratings may, however, provide an important alternative perspective to that of the child. However, this does raise important issues about how information from different informants is combined or compared.

The developmental aspects of QoL have not been well studied. It is likely that there will be major age-related differences in the way individuals value different aspects of QoL, the ways in which they can express these and the ways that these two factors interact. It is inevitable that in selecting an instrument for a particular age group one will have to trade-off the age specificity of item content with the benefits of potential comparability across ages [48]. If one focuses too much on adapting instruments for use by a specific age group then it is likely to become difficult to compare or to pool data collected from subjects of different ages. On the other hand, if an instrument does not cover the necessary constructs within an age then the validity of that instrument will inevitably be compromised. Careful piloting of proposed instruments within the age range to be studied is therefore essential. There are various ways that instruments can be tailored to make them more age appropriate. These include; ensuring that questionnaires are short and written in simple (age appropriate) language; changing questionnaires into interviews [36, 63]; attempting to reduce the influence of the adult over the child's responses during face-to-face administration; using pictorial response formats such as smiley, neutral and sad faces [17, 24, 34, 61]; using props and puppets [49]; computeradministered measures [23, 31]; and ensuring that an appropriate recall period is selected. Younger children can have difficulties with the time concepts such as 1 week or 1 month [63].

In addition to these general issues relating to the measurement of QoL in children there are issues which are more specifically related to mental health problems in children. Mental health disorders will interact in complex ways with QoL. Mental health difficulties impact on a person's capacity to engage effectively in daily activities and this can have knock-on consequences for their general sense of well-being. A reduced sense of well-being can also impact on mental health by, for example, further lowering mood. In childhood, the effects of mental health difficulties on QoL are perhaps most obvious in the more severe or extreme forms of mental health problem (e.g. autism) or those that impact directly on an individual's sense of self worth (e.g. anxiety and depression). However, there is growing evidence that the, so called, externalizing disorders such as oppositional defiant disorder and attention deficit/hyperactivity disorder (ADHD) also substantially reduce the QoL of children and young people in terms of their subjective sense of wellbeing and their capacity for everyday functioning.

The goal of this review is to address the issue of QoL in ADHD through a systematic review of the published literature. ADHD is a high prevalence disorder of childhood and adolescence marked by early onset, persistent and pervasive patterns of inattention, overactivity and impulsivity. It is associated with impairment across a range of domains. More specifically ADHD is associated with educational under-achievement [94], family-related and peer relationship problems [2, 3, 25] and increased anti-social and delinquent activity [72]. Long term adverse outcomes include increased risk of substance abuse [14], reduced vocational opportunities [5] and increased criminal activity [73]. ADHD is often comorbid with other disorders such as oppositional defiant disorder (ODD), conduct disorder (CD), depression and anxiety $[11,12]$. ADHD can be successfully managed by a combination of stimulant medication and psychosocial approaches which reduce both symptoms and global levels of impairment. While generally well tolerated stimulant medication has a range of sideeffects in a substantial minority of children [4, 6, 30].

Understanding the impact of mental disorder in general and ADHD in particular on QoL can be informative on a number of levels. QoL has the potential to be an important outcome measure. Indeed Spitzer and colleagues have 
suggested that the main goal of healthcare is to improve patients perceptions of their health and the extent to which health problems interfere with their QoL [79]. It could be argued that QoL outweighs simple short-term symptom reduction as the most important treatment outcome for ADHD. If a treatment reduces symptoms but does not increase a child's QoL can that treatment be considered effective? Thus QoL, if able to be measured reliably could be an important outcome measure in both clinical research and routine patient care. On a more general level the use of QoL data by individual child and adolescent mental health services could assist with service planning and audit—and help focus attention on outcomes that patients themselves feel are important. Taking this one step further the assessment of QoL across different mental and physical health domains can allow for direct comparisons to be made between the impacts of these conditions on either individuals or populations - which in turn has the potential to provide an evidence base for a more rational reconsideration of the ways that resources are allocated within health services than is typically the case. QoL measurement is already acknowledged as being central to the calculation of cost-effectiveness of different treatments and hence to the choices between treatments, both at an economic level (e.g. reimbursement of drug treatment costs) and at an individual patient level [21].

In order that these goals can be achieved, with respect to ADHD, several key questions need to be addressed. These include; (1) what is the impact of ADHD on QoL? (2) What are the relationships between ADHD symptoms, functional impairment and the mediators and moderators of QoL in ADHD? (3) Does the treatment of ADHD impact on QoL? This paper will address progress to date in trying to find answers to these questions through a systematic review of the published literature pertaining to QoL in ADHD, identify gaps in knowledge and make suggestions about the future lines of investigation that will be required to further the field.

\section{Methods}

A systematic literature search was conducted using the following databases; Ovid MEDLINE (R), Cochrane database of systematic reviews, ACP Journal Club, DARE, CCTR, CMR, HTA, NHSEED, EMBASE and PsychINFO from 1988 to April 2008. Text word and thesaurus searches were used to minimize the chance of missing relevant articles. The following keywords were searched: child, childhood, children, pediatric, paediatric, adolescent; quality of life, QOL, HRQOL, health status, functional status, well-being; self-esteem, self-concept, self-competence and self-image; ADHD, Attention deficit hyperactivity disorder, attention $\times$ disorder. The reference lists of identified papers and previous reviews of QoL in children were searched manually. Included were papers in one of five major European languages (English, German, French, Italian, Spanish). Other inclusion criteria were; publication in a peer reviewed journal; a study, of any design, focusing on QoL in children or adolescents with ADHD that contained at least some empirical data on QoL measurement in children or adolescents with ADHD and used a QoL instrument. Studies in adults were excluded. The titles and abstracts of all papers identified from the first search were read by two authors (MD, DC) where there was disagreement at this stage the paper was retained. The full text of those papers passing this screen was read independently by two of the authors (MD, DC). There was full agreement between these two authors at this stage. Data was extracted by MD and checked for accuracy by DC and E S-B. Where there were several publications from single studies these were included where there was not repetition in the data presented. Where there were meta-analyses these were included and discussed before the individual studies.

The results of identified studies are described in a descriptive manner with effect sizes reported where available. As a guide to interpreting the clinical meanings of these effect sizes Norman et al. [53] proposed that, in QoL research, a difference of at least half a standard deviation is required for a "clinically meaningful difference."

\section{Results}

This broad search strategy resulted in a total of 1,445 articles (including duplicates) from which a total of 36 relevant articles were identified (Fig. 1, Tables 1,2).

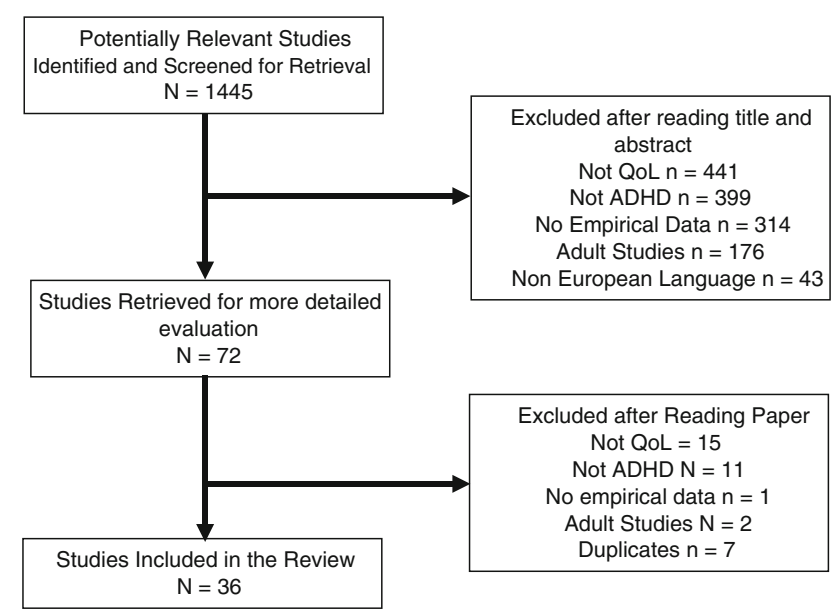

Fig. 1 QUOROM flow chart for literature search 


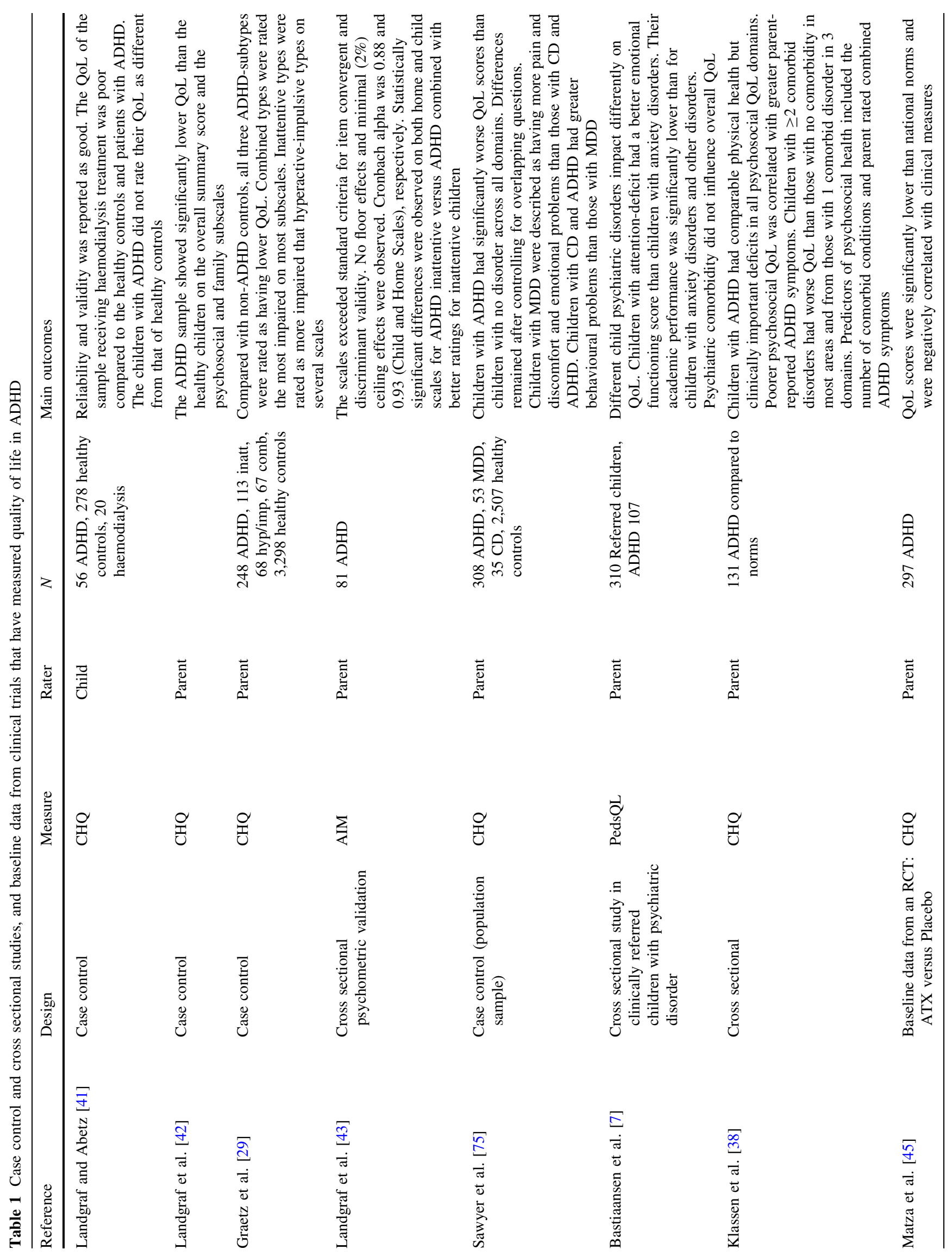




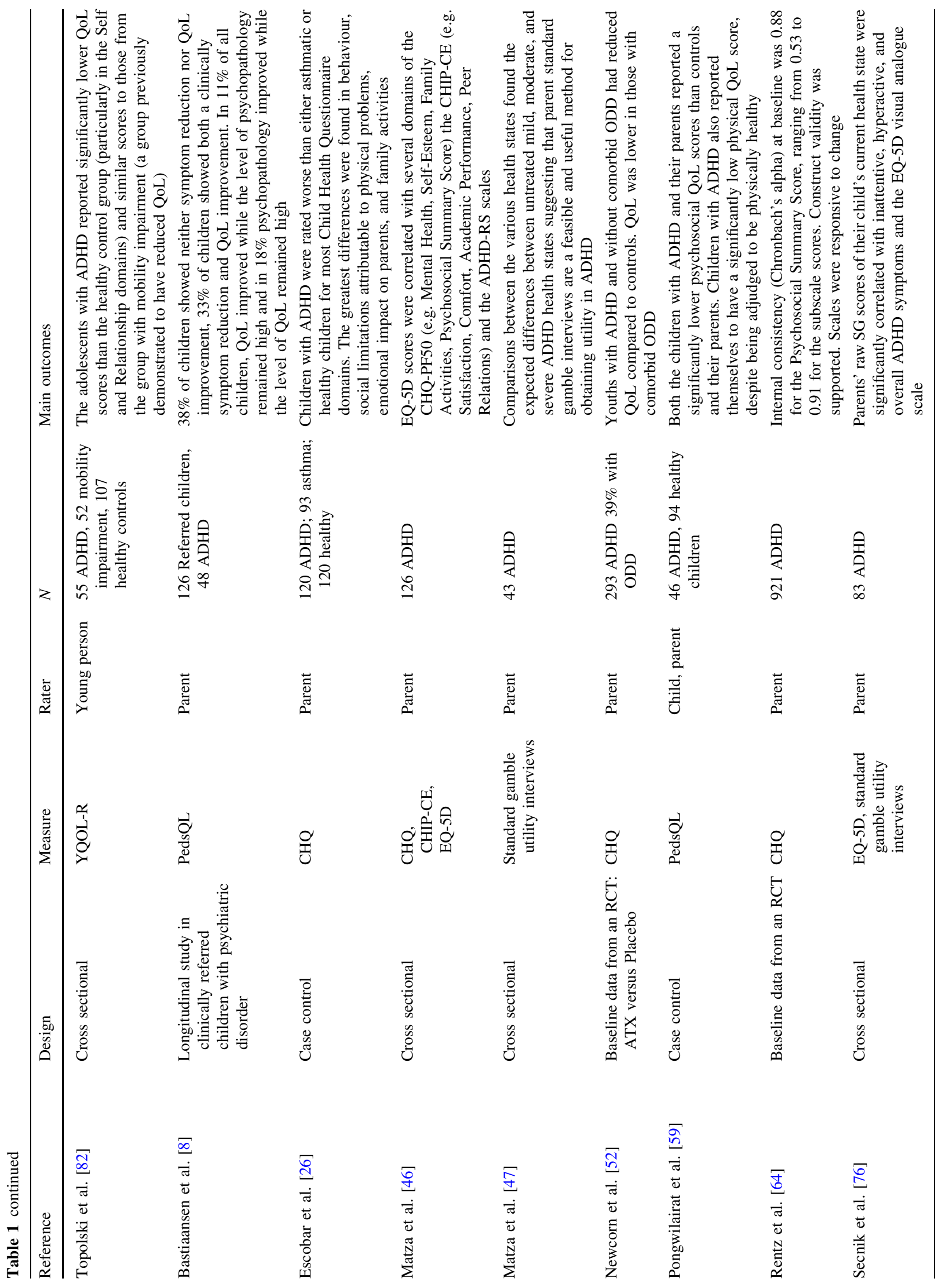




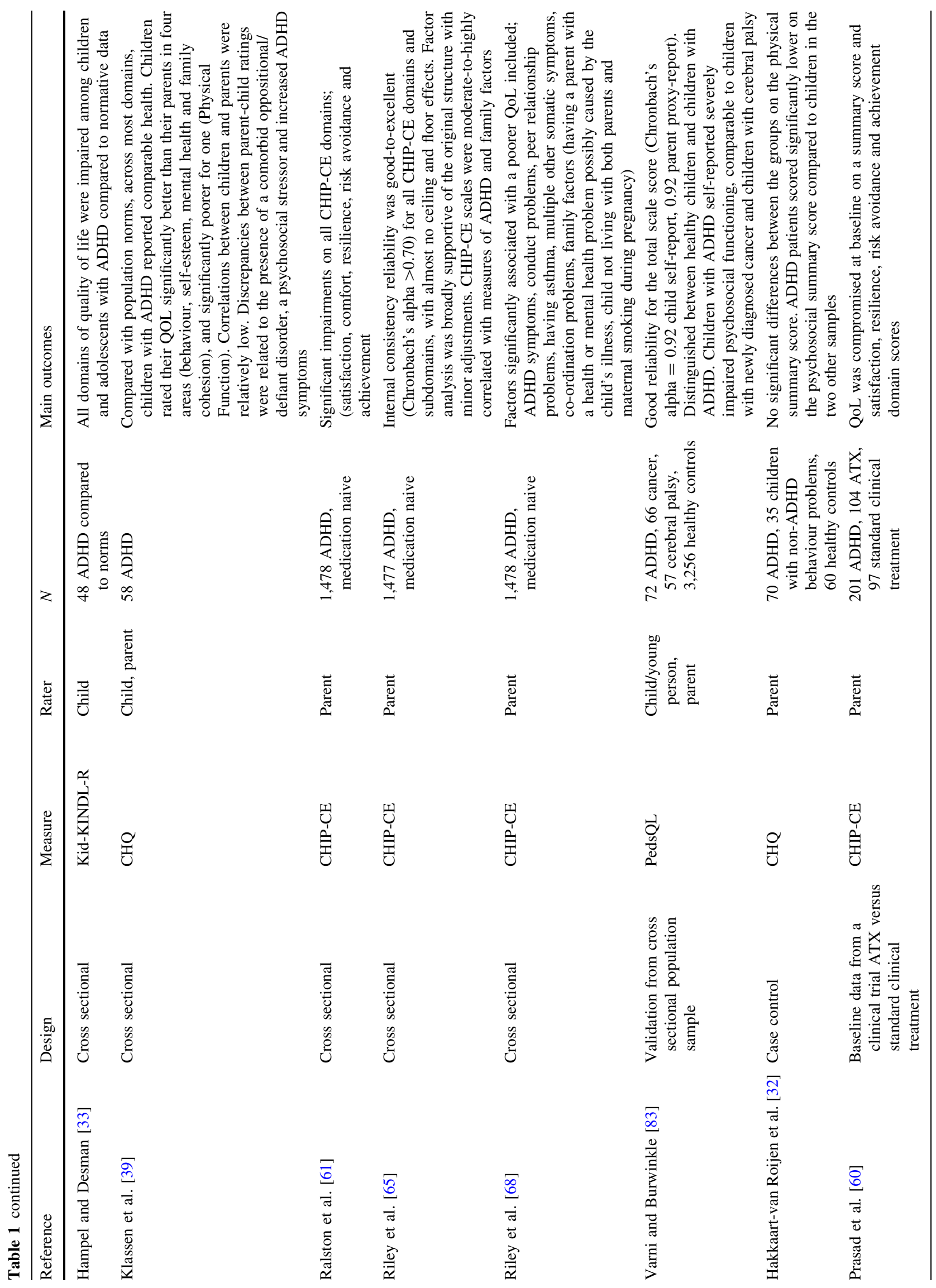




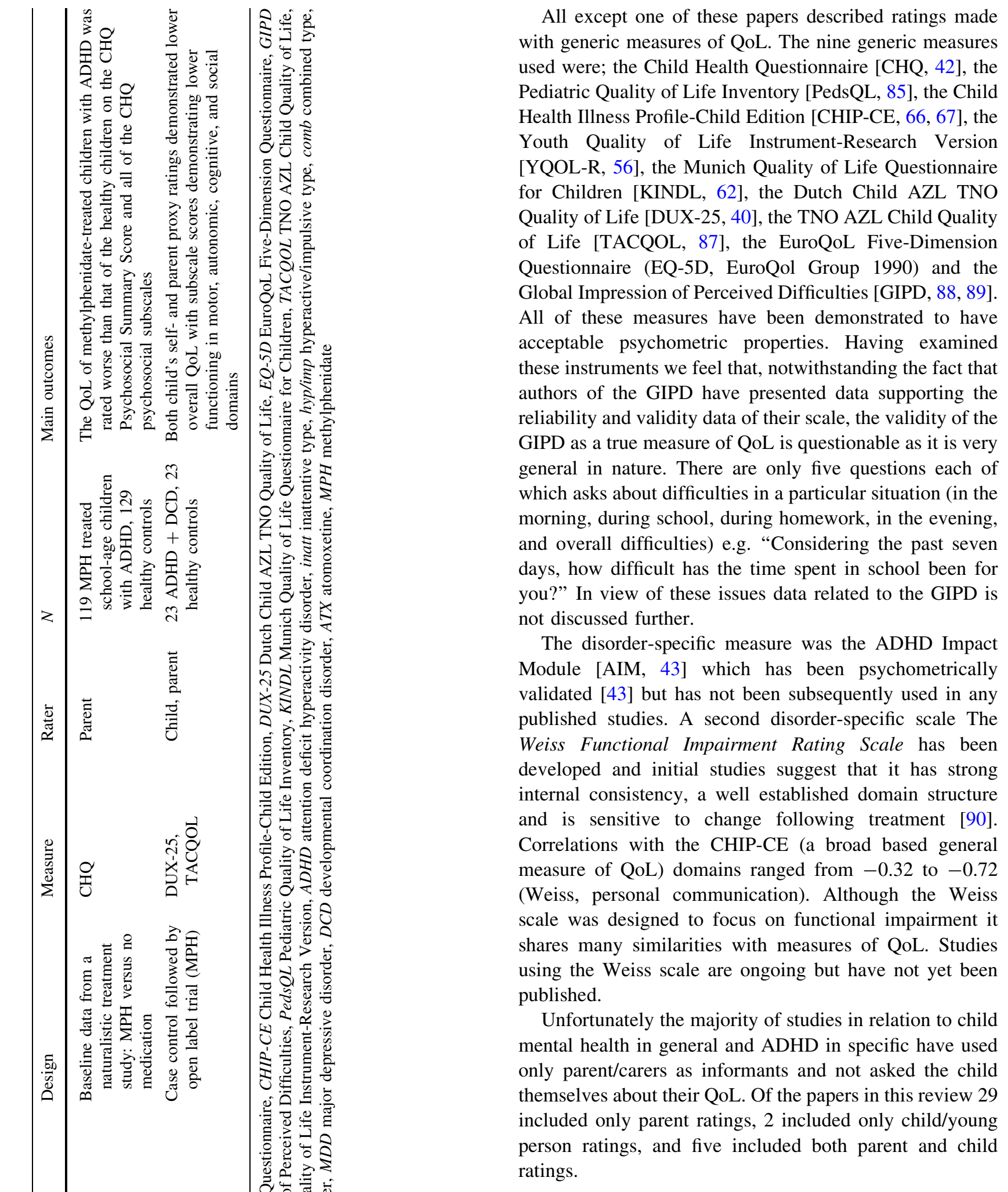

\section{What is the impact of ADHD on QoL?}

Identified case control and cross sectional studies of QoL in ADHD are described in Table 1. 


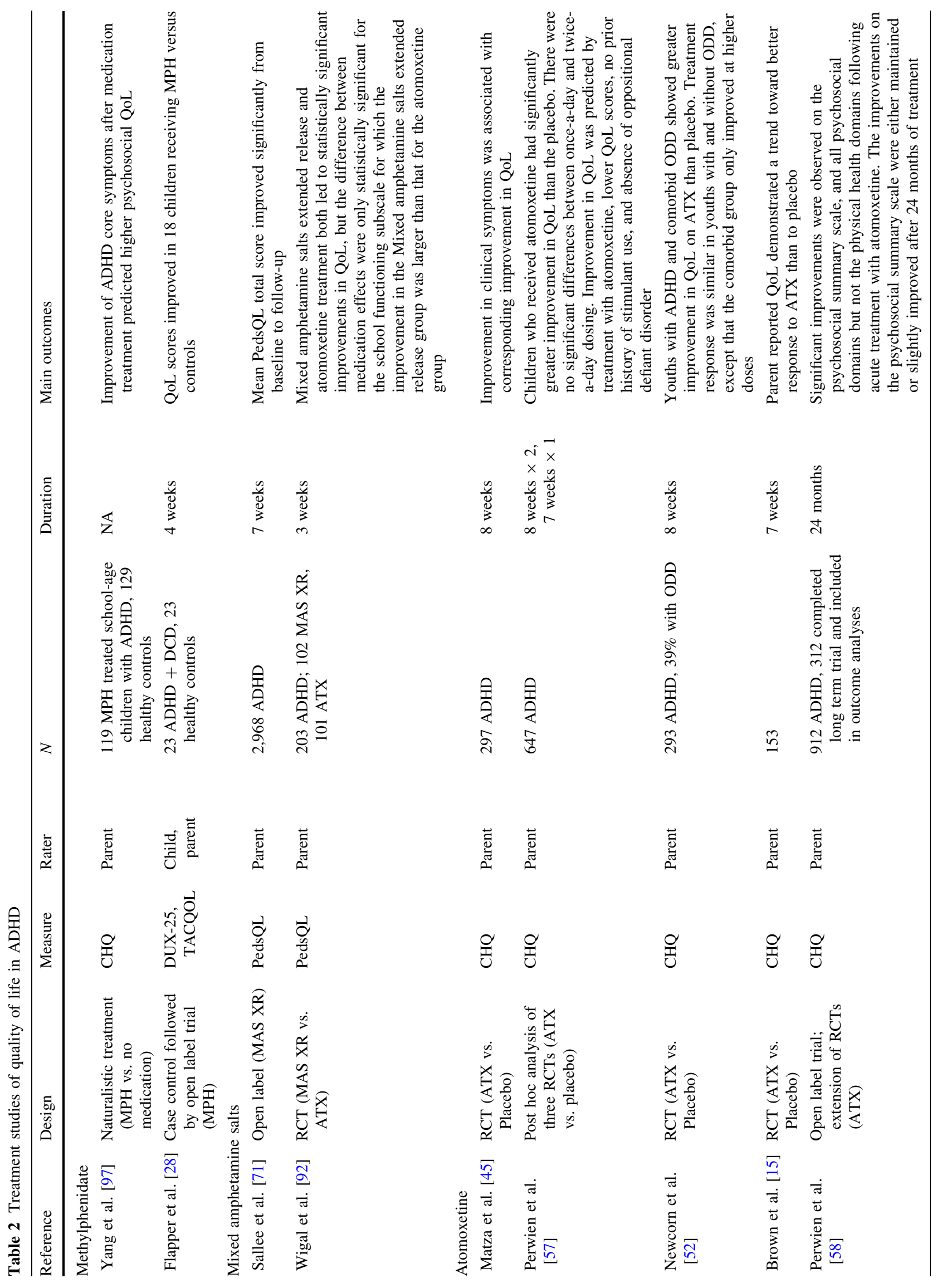




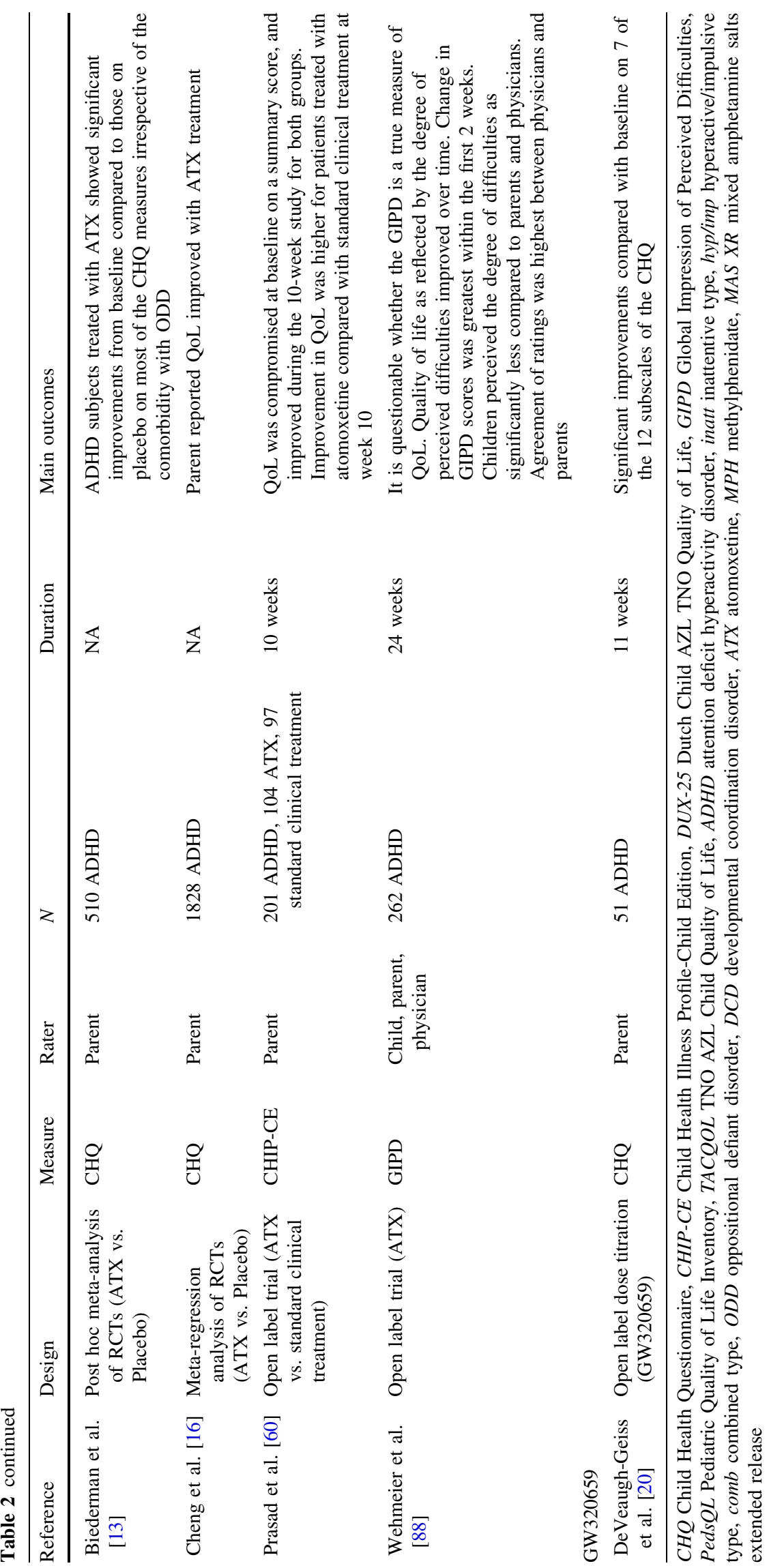


QoL in children with ADHD compared to healthy children

With two exceptions [75, 83] all of the studies which have investigated QoL in children or adolescents with ADHD have been conducted using clinical samples of referred children.

\section{Self-report}

Despite the considerable importance invested in the individual's self-perceptions by most definitions of QoL, only 7 studies of the QoL of children with ADHD that included child ratings were identified. Two studies used the CHQ, both of which failed to find a difference between ADHD and controls. Landgraf and Abetz [41] found that children with ADHD (9-16 years) reported their QoL to be very similar to that of healthy controls across the nine domains of the self-report version of the CHQ-CF87. Klassen et al. [39] also found that children and adolescents with ADHD (10-17 years old) rated their own QoL as no different from the general child population across most of the CHQ-CF87 domains. Compared to a healthy control group they considered themselves to be equal with respect to overall QoL, and on the role/social functioning, general health perceptions, bodily pain/discomfort, mental health, self-esteem and parental impact, slightly worse for physical function and behaviour and significantly worse only for family activities. The Klassen et al. study also compared child and parent CHQ ratings. Children rated their QoL significantly more positively than did their parents for their behaviour, self-esteem, mental health and family cohesion and significantly poorer for physical function. In general there was greater agreement between children and their parents for the physical subscales (with correlations between $r=0.75$ and $r=0.60$ ) than for the psychosocial subscales (between $r=0.40$ and $r=0.48$ ). Using the KINDL [62], Hampel and Desman [33] also found all domains of quality of life to be impaired in children and adolescents with ADHD compared to normative data.

In contrast to these findings with the CHQ and the KINDL several studies using different measures did find that children with ADHD self-report reduced QoL compared to healthy children. Topolski et al. [82] using the YQOL-R [22, 56], found that adolescents with ADHD (11-18 years) reported poorer QoL, compared with a control group without a chronic health condition, especially in the domains of self (belief in self, mental and physical health) and relationships (peers, friends, family, adults). These differences were no longer statistically significant, however, when a Bonferroni correction for multiple comparisons was applied. Pongwilairat et al. [59] using the PedsQL [86], in a Thai sample also found lower self rated
QoL in children with ADHD. The total score and the physical and psychosocial domain scores on the PedsQL reported by children with ADHD were all significantly lower than those reported by control children. These differences remained when corrected for medication status. Varni and Burwinkle [83] also found that, compared to healthy children, ADHD children (5-16 years) reported significantly lower PedsQL scores on dimensions of psychosocial health and small, but not statistically significant differences on physical functioning in a large populationbased study. They also reported that the parent and child ratings were similar across all domains, that the inter-correlations of the PedsQL subscales between the two raters were in the medium to large range (between $r=0.50$ and $r=0.75$ ), and that the correlations in the physical domain were similar to those for the psychosocial domains [83]. Rimmer et al. [69] reported similar correlations $(r=0.67)$ between child and parent ratings on the PedsQL in an independent clinic based sample. Using the DUX-25 [40] and TACQOL [87] in a Dutch clinical sample of children with both ADHD and developmental coordination disorder (DCD) Flapper et al. [28] also found lower overall QoL in the ADHD/DCD group on both measures with subscale scores on the DUX-25 demonstrating lower functioning on the emotional and social domains and the TACQOL lower functioning on the motor, autonomy, cognitive, social and positive moods domains.

\section{Parent rated}

Twenty-three studies were identified that compared parent rated QoL in samples of children and adolescents with ADHD with that of normal controls or against existing normative data on QoL from standardized instruments. During the development of the parent version of the Child Health Questionnaire (CHQ-PF50), Landgraf et al. [42] reported that an ADHD sample were rated as having significantly lower scores on the psychosocial summary score and the psychosocial and family subscales (behaviour, mental health, self-esteem, role limitations-emotional/ behavioural, parental impact-emotional and time, family activities and family cohesion), compared to their norm group. These findings were replicated in several clinical ADHD samples which used the CHQ and compared children with ADHD to either healthy controls [26, 32, 75] or US norms [15, 38, 39, 45, 46, 52, 57, 58, 64, 97]. Differences have been reported for both male and female subjects. The largest differences have been found on the family impact (family activities, parental time emotional), behaviour and role-emotional/behavioural subscales. The psychosocial summary scores for children with ADHD in the different studies are between 1.5 and 2 SD below the US norms. Comparing different ADHD-subtypes on the 
$\mathrm{CHQ}$, all three subtypes had worse scores than controls on most subscales although only the inattentive subtype were impaired on the physical subscales. There were other differences between the groups, for example, the combined and inattentive subtypes had significantly lower scores on the self-esteem and emotional impact subscales than the hyperactive-impulsive type and the combined subtype in turn showed worse scores on the, role/social functioning (due to emotional and behavioural problems, family activities and impact on parental time subscales than both the inattentive and hyperactive-impulsive subtypes [29]. Parents did not rate children with ADHD to have lower QoL on the physical domain in most studies $[38,45,57$, 64]. However, in a large community sample Sawyer et al. [75] did find small but significant differences on the parentreported physical subscales of the CHQ-and the study of Escobar et al. [26] also reported a significantly lower physical summary score in children with newly diagnosed ADHD, compared to a control sample. Klassen [37] computed the effect sizes for several of the above studies, using the CHQ-PF 50 using the criterion of Norman et al. [53] clinically meaningful deficits in QoL were reported on all psychosocial and family subscales (mental health -0.55 , self-esteem -0.75 , parental impact time -0.85 , roleemotional/behavioural -1.22 , behaviour -1.44 , parental impact-emotions, -1.45 and family activities -1.67 ).

Using the PedsQL both Pongwilairat et al. [59] and Varni and Burwinkle [83] found children with ADHD to have similar parent rated QoL for physical health compared to healthy controls. This contrasts with the lower total and psychosocial, emotional, social and school subscale scores on the ratings of the ADHD group reported in the same studies.

In a pan-European ADHD observational study [ADORE, 59], the QoL of some 1,500 children with ADHD was dramatically lower at baseline, than that of norms for community youth, with mean scores on the parent report form of the CHIP-CE [67] between 1.5 and 2 standard deviations below community norms in all domains, except for the comfort domain. Scores were below 35 (mean of 50 with SD of 10) for the sub-domains, satisfaction with self, social problem solving, threats to achievement and academic achievement and between 40 and 35 for satisfaction with health, emotional comfort, family involvement, individual risk avoidance and peer relations. Only three subdomains were near normal: physical comfort, restricted activities and physical activities. These findings were consistent across all ten participating countries [65]. Equally compromised QoL, as measured by the CHIP-CE, was found in 200 children with ADHD entering an open label treatment study in the UK [60].

Hampel and Desman [33] found all domains of parent reported QoL to be impaired among children and adolescents with ADHD compared to normative data using the KINDL [62] and Flapper et al. [28] also reported reduced overall parent rated QoL in their group of children with ADHD and DCD on both the parent rated DUX-25 [40] and TACQOL [87] measures with subscale scores on the DUX-25 demonstrating lower functioning on the physical, home, emotional and social domains and the TACQOL lower functioning on the motor, autonomy, cognitive, social and positive and negative moods domains.

In two linked studies, one in the UK and one in the US, that used the EQ-5D parent version [27], very few of the parents of children with ADHD-related problems reported difficulties on the physical items (e.g. mobility and pain/ discomfort) while the majority endorsed that their children had problems with emotions and in their abilities to carry out usual activities [46].

In summary, robust reductions in QoL of around 1.5-2.0 SD are reported across several different QoL measures and across a broad range of psycho-social, achievement and self evaluation domains by the parents of children with ADHD. Clearly these are large effects which are similar in size to those reported for the ADHD symptoms [93]. In general no strong effects of ADHD on physical functioning domain of QoL are reported. This negative impact is seen in both boys and girls and across the different ADHDsubtypes. Although not well studied the impact of ADHD on QoL appears to be less robust and broadly based when self-reported QoL is the main outcome. Children with ADHD rate their own QoL less negatively than do their parents and do not always consider themselves as having impaired QoL compared to healthy controls. These differences between parents and children may be related to the measures used. It is notable that while no group differences were reported for the two studies that have used the CHQ reduced self-reported QoL was reported in the four studies in which other QoL measures were used. Comparative studies would be helpful in identifying whether this is a consequence of the limited number of studies or the way in which the child completed CHQ has been constructed or worded (the same pattern of results was not found for the parent completed studies). However, it is also possible that the less robust findings are due to either a lack of self awareness or minimization of difficulties on the part of the ADHD child cannot be ruled out. Alternatively parents' ratings may be influenced by their own burden of care. There clearly needs to be more effort put in to studying self-reported QoL in those with ADHD and future studies should consider comparing ratings across different measures and comparing and analyzing the differences between child and parent ratings of QoL. It would also be of interest to use interviews in parallel with the standard questionnaires to investigate the meaning of different QoL scores and to tease out whether some questions are more sensitive/ 
important at picking up problems than others in this group of children and young people.

QoL in children with ADHD compared to children with other conditions

In order to assess the significance of the effects of ADHD on QoL it is useful to compare QoL in ADHD with QoL in other physical and mental health conditions. Whilst it would be possible to make indirect comparisons by comparing data from the many separate studies that have investigated QoL in different conditions this would result in a wide range of methodological problems. We have therefore restricted ourselves to studies that have made direct comparisons.

Three comparative studies have compared child selfreported QoL in children with ADHD and other medical conditions with conflicting results. Children with ADHD rated their QoL far better than children with end stage renal failure, not only on the physical subscales but also on role/ social behaviour and mental health using the CHQ-CF87 [41]. On the PedsQL children with ADHD reported; significantly better physical functioning compared to children with newly diagnosed cancer and children with cerebral palsy; lower psychosocial health and social functioning (but similar total scores and emotional and school functioning) to the children with cancer and comparable total scores and psychosocial, emotional, social and school functioning to the children with cerebral palsy [83]. In the study by Topolski et al. [82] adolescents with ADHD reported similar scores on the YQOL-R to those from a group of adolescents with mobility impairment, who had previously been demonstrated to have reduced QoL compared to healthy children. It is interesting to note that as in the previous section, comparing child reported QoL between children with ADHD and healthy controls, it was only the study using the CHQ that reported the ADHD group to be generally better than those in the physical problems group.

Several studies have used parent proxy measures of QoL in comparative studies. Compared to children with asthma and sickle cell disease, children with ADHD were rated as having a lower QoL on the psychosocial subscales of the CHQ-PR50 while being given better scores on the physical subscales [45]. Escobar et al. [26] confirmed these findings also using the CHQ in a comparison between children with newly diagnosed ADHD and asthma. In the study of Varni and Burwinkle [83] the pattern of impairments reported by parents was different to that of the children themselves. Whereas the children with ADHD had reported similar total scores on the PedsQL to children with cancer and cerebral palsy their parents rated their overall QoL as superior to that reported by the parents of the two physical disorder groups.
There have been several direct comparisons of parent rated QoL between ADHD and other mental health conditions. In a large community sample, the QoL of children and adolescents with different mental disorders was compared after the exclusion of comorbid cases [75]. The results were all in the predicted direction. Children with ADHD had more behavioural and fewer emotional problems than those with major depressive disorder, and also had more interference with family activities and impact on parental time (effect sizes all $\geq 0.3 \mathrm{SD}$ ). Interference with peer and school activities or emotional impact on parents varied little for children as a function of different mental disorders. No significant differences were found between children with ADHD and conduct disorder. In the same study the scores of children with mental disorders (a majority of who had ADHD) were significantly lower on four of the five CHQ scales than for children with physical disorders (including asthma, diabetes and epilepsy). In a clinical sample, Bastiaansen et al. [7] did not find any overall differences in QoL of children with ADHD/disruptive disorders compared to those with other psychiatric disorders such as anxiety disorders, pervasive developmental disorders, mood disorders or even to those for whom help was being sought but who at assessment did not warrant a formal psychiatric diagnosis. However, children with disruptive disorders including ADHD showed significantly lower scores on the psychosocial sub-domain of the PedsQL than children in the other or no diagnosis category. Using the Dutch version of the CHQ PF-50 Hakkaart-van Roijen et al. [32] found that parents of ADHD children reported their children to have poorer QoL on the psychosocial summary score compared to the reports of parents of children with "non-ADHD behavioural problems."

In summary, ADHD has been shown to have a comparable overall impact on QoL when compared to physical disorders. However, a closer inspection suggests greater impact on psychosocial QoL domains, and a lesser impact on physical QoL domains than common chronic physical illnesses. Initial evidence also suggests that ADHD has a comparable overall impact on QoL when compared to other mental health conditions. The available data is starting to suggest that different mental health disorders may impact on some QoL domains (e.g. peer and school problems and impact on parents) in similar ways while on other domains the impact varies depending on the disorder (e.g. children with ADHD had more behavioural problems and interference with family activities, but fewer emotional problems than those with major depressive disorder). However, data on these issues remains sparse and more studies are required before any clear statements can be made. Such data will be important not only to clinicians but also to health service planners who are required to make decisions about resource allocation between different parts 
of comprehensive children's healthcare services and within different parts of child and adolescent mental health services.

Factors related to QoL in ADHD; Symptom severity, impairment, comorbidity, demographic and other factors

If we are to fully understand the nature of the QoL impairments in ADHD it is necessary to examine the factors that may drive a reduction in QoL.

\section{Symptom severity}

Several studies have investigated the correlations between symptom severity and QoL scores. Clearly an absence of correlation would be surprising and cast doubt on the relationship between ADHD and QoL. On the other hand a perfect or very high correlation would lead one to question whether the two concepts were in fact separable and whether measuring QoL adds anything to our understanding of the child with ADHD. A significant but moderately strong correlation supports the notion that QoL and ADHD symptoms are related but distinct constructs and that both may be required to give a full picture of a child's difficulties.

The scores on the psychosocial scales of the CHQ-PF50 have been shown to significantly negatively correlate with parent and clinician symptom ratings [38, 45, 64]. Correlations are usually in the small to moderate range (between $r=-0.21$ and $r=-0.60$ ), which suggests that these measures are tapping into related but distinct constructs. The highest correlations with symptom severity are found on behaviour and family activities subscales. The psychosocial subscales correlated equally highly with both the hyperactivity/impulsivity and the inattention symptom subscales [38, 45]. Correlations between the parent-reported QoL psychosocial scores and the teacher-reported Child and Adolescent Symptom Inventory were not statistically significant [38]. High symptom scores also predicted poor QoL on parent ratings using the CHIP-CE in the ADORE study [68]. Coghill et al. [19] using the EQ-5D found that utility scores deteriorated as severity increased and that patients with improved symptom severity since the last consultation had higher utility values $(0.88)$ than those who did not improve (0.78). This suggested that patients who had reduced symptom severity valued their health state more than those whose symptoms did not improve. Similar results were reported by Matza et al. [47]. Used standard gamble (SG) utility interviews to assess parent preferences for health states of childhood ADHD. Parents' SG rating of their child's current health state was significantly correlated with inattentive, hyperactive, and overall ADHD symptoms $(r=0.37,0.36$, and 0.40 , respectively; $p<0.05)$ and psychosocial HRQL domains, the mean utility score was 0.74 (on a utility scale ranging from 0 to 1). Secnik et al. [76] conducted a similar study in the UK and again found that parents' raw standard gamble scores of their child's current health state were significantly correlated with inattentive, hyperactive, and overall ADHD symptoms and the EQ-5D visual analogue scale.

\section{Functional impairment}

While it is possible to have a serious physical disorders such as diabetes, hypertension or cancer without there being any obvious functional impairment for ADHD, and most other psychiatric disorders, both symptoms and functional impairment are a prerequisite for diagnosis. Accordingly clinical guidelines have encouraged the measurement of both and instruments such as the Children's Global Assessment Scale (CGAS) [77] have been developed to allow impairment to be routinely measured in a clinical setting [80]. There are both similarities and differences between the concepts of impairment and QoL. Impairment is an objectively measured assessment of a deviation from the mean for a broad range of functional domains. QoL relates to similar domains but measures them subjectively against an internally rather than externally generated standard. Impairment is usually rated or measured by the clinician, QoL by the patient; impairment is integral to the illness; QoL is a broader assessment of the impact of illness [75]. Some of these differences are reflected in the differences between the CGAS and measures of QoL. As it involves making a single very general rating the CGAS, would not be expected to capture the diversity of QoL domains or the distinctiveness of the parent or the child perspectives. Using the PedsQL Rimmer et al. [69] found relatively low correlations between parent and child ratings of QoL and clinician ratings of severity using the CGAS (parent/clinician $r=0.42$; child/clinician $r=0.29$ ). Poor scores on the Clinical Global Impressions scale [CGI-S, 51], which indexes the severity of the disorder, were predictive of lower QoL as measured by parent ratings on the CHIP-CE in the ADORE study [68]. It is important to note that as some aspects of impairment are heavily reliant on self or proxy reports (e.g. ability to keep friends or build up close relationships) the boundaries between the impairment and QoL constructs are not always clear cut and much more work is required to more clearly define their boundaries and overlaps. However, as is the case for symptoms the finding of significant but not perfect correlations between impairment and QoL in ADHD adds some weight to the validity of the QoL construct in this context and that QoL is not simply a relabelling of impairment, as measured by tools like the CGAS, by a different name. 


\section{Comorbidity}

Several studies have suggested that children with ADHD and a comorbid disorder have poorer QoL than those with ADHD alone. Newcorn et al. [52] compared youth with ADHD with and without ODD, and found that those with ODD generally had lower scores on the psychosocial summary score of the CHQ-PF-50, as well as on most subscales. The presence of a psychosocial stressor (e.g. parental separation/divorce; move; conflict with siblings or peers) was also related to a larger difference in the behaviour scale in this study, and higher parent-reported ADHD symptom severity was associated with more negative findings for self-esteem [52]. Within a sample of clinically referred children with ADHD multiple comorbid disorders was associated with poorer psychosocial $\mathrm{QoL}$ on the CHQ-PF50 than having either no or only one comorbid disorder [38]. The combination of comorbid ODD/CD and another comorbid disorder (e.g. tic disorder, depression, anxiety disorder but not learning disability) was also associated with significantly lower scores [38]. In a separate study by the same group discrepancies between parent and child reports of the CHQ behaviour and mental health scales were larger in the presence of ODD/CD [39].

In the ADORE study the association between 26 independent factors including comorbid problems and ADHD children's QoL was investigated using the CHIP-CE [68]. The presence of high emotional symptoms, conduct problems, peer relationship problems, coordination problems, asthma or two or more somatic symptoms, and having a parent with mental health or health problems, were all associated with poor parent-reported QoL on the CHIP-CE over and above the association between ADHD and QoL.

\section{Demographic and other factors}

In the ADORE study several other baseline variables, including several family factors, such as having a parent with a health or mental health problem possibly caused by the child's illness, child not living with both parents and maternal smoking during pregnancy were also associated with poorer QoL. Other factors such as the number of children living at home, a history of parental ADHD, maternal drug/alcohol abuse during pregnancy and low birth weight or prematurity were not associated with QoL scores on any domain/sub-domain. Living with both parents was, however, associated with a stronger sense of well-being [68].

In summary, the available data supports the validity of QoL measures as being associated with, but not completely overlapping with, ADHD symptomatology and impairment. Increased symptom levels and impairment predict poorer QoL. The presence of comorbid conditions or psychosocial stressors is also predictive of poorer QoL in samples of ADHD children. Further studies are required to extend our understanding of the predictors and correlates of reduced QoL. These data should also be examined in detail to gain a better understanding of the overlaps between the various frames of reference (symptoms, impairment and QoL) and this information fed back so into efforts to refine the structure and scoring of current measures and the development of new and improved measures of QoL.

Is QoL in children with ADHD responsive to treatment?

If QoL measures are to be useful as outcome measures it is essential that they are sensitive and reliable measures of, change and are able to and capture changes that may occur in QoL after treatment. In their review of QoL measures in children and adolescents Solans et al. [78] reported that acceptable sensitivity to change has been reported for only $10 \%$ of the identified generic instruments (CHQ, KIDSCREEN, KINDL and Peds-QL). However, those that were tested were found to be sensitive to changes down to around 0.2 standard deviations. Of these four measures only the CHQ and the Peds-QL have so far been used in treatment studies of ADHD. Studies in paediatrics have generally supported the use of QoL as an outcome measure [84] although this remains a relatively understudied field that has only become popular to study in recent years. Within the child and adolescent mental health field we believe that QoL has only been used as an outcome in clinical trials for ADHD. The studies that were identified which measured treatment related changes in QoL in ADHD studies are described in Table 2.

We are unaware of any published clinical trials of psycho-social treatments for ADHD that have utilised QoL measures of outcome. However, early data from the longitudinal aspect of the ADORE study do suggest that over the first 3 months of treatment psychosocial treatments (mainly psychoeducation) are associated with an improvement in aspects of QoL, although these changes are not as great as those seen for pharmacological treatments [81].

Several studies have investigated the impact of medication treatments on QoL. Unfortunately as these studies have only recently started to appear in the literature and there are very few published studies describing the impact of either methylphenidate or amfetamines on QoL. There is, however, a fairly sizable literature on the effects of atomoxetine on QoL. All currently published treatment studies have used generic QoL scales rather than ADHDspecific scales. 


\section{Methylphenidate}

There are no published controlled trials which have investigated the impact of methylphenidate treatment on QoL. In a cross sectional observational study of QoL, while both stimulant medicated and un-medicated children with ADHD had significantly lower total and psychosocial subscales scores on the PedsQL than healthy controls and these two groups did not differ from each other [59]. In another observational study Yang et al. [97] using the CHQ-PF50 also found the Psychosocial Summary Scores and all of the psychosocial subscale scores of children treated with methylphenidate were poor compared to healthy controls. However, they also reported that improvement of ADHD core symptoms after medication treatment was predictive of higher psychosocial functioning. This effect was independent of the child's current age, age at receiving diagnosis, age starting and duration of medication treatment but was not independent of ADHD comorbidity: The QoL of those children with a comorbid condition was less likely to improve even if core ADHD improved [97]. Flapper et al. [28] investigated the effects of methylphenidate at "optimal dose" in known responders in an open label trial on the parent and child rated DUX-25 and TACQOL. Children on methylphenidate rated themselves and were rated by their parents as having improved total QoL scores compared to their un-medicated state on both instruments and improved scores on the child reported physical and emotional subscales of the DUX-25, the child reported autonomy, cognitive, social, and negative moods subscales of the TACQOL and the parent-reported bodily, motor, autonomy, cognitive and social subscales of the TACQOL.

\section{Amfetamines}

One open label [71] and one randomized controlled double-blind trial (RCT) [92] have investigated the impact of mixed amfetamine salts on QoL. Both studies were sponsored by the pharmaceutical industry. In the open label study almost 3,000 subjects were treated with an extended release mixed amfetamine salt (MAS) preparation over a 7 week period [71]. QoL as measured by the total score on the parent rated PedsQL improved significantly from baseline to endpoint. Wigal et al. [92] measured QoL using the PedsQL during a randomized controlled double-blind laboratory school study comparing this same extended release mixed amfetamine salt preparation with atomoxetine. Both treatments resulted in statistically significant improvements in QoL from baseline to endpoint. The mean difference from baseline on the PedsQL for MAS was 7.9 unit points and for atomoxetine was 7.1 unit points $(p<0.0001)$. There were no differences between the two medications with respect to the total ADHD scores or the ADHD symptom subscale scores. The two treatments did, however, differ with respect to QoL was seen on the school functioning subscale on which there was a greater improvement in the amfetamine treated group (34\%) compared to the atomoxetine treated group $(25 \%)$. The least square mean difference of 6.94 unit points $(95 \% \mathrm{CI}$, $-2.45,11.42$ ) indicated a positive effect of MAS over atomoxetine, a difference that was statistically significant [92].

\section{Atomoxetine}

This has been the most extensively studied ADHD medication from the perspective of QoL. Again all studies have been sponsored by the pharmaceutical industry. Combining data from three randomized double-blind controlled trials, Perwien et al. [57] documented that improvements on atomoxetine over and above those seen on placebo in the psychosocial summary score $(d=0.55, p=0.0001)$, but not the physical summary score $(d=-0.11, p>0.05)$. Significant improvements were also found for the behaviour, family activities, parental impact time, role emotional/ behavioural and mental health scale scores $(d=0.26-$ $0.55, p<0.05$ ) of the parent rated CHQ-PF-50. Benefits were demonstrated after 7-8 weeks treatment. Lower baseline QoL scores, no prior stimulant use and absence of ODD were associated with improved QoL at endpoint. No difference was found between once or twice daily dosing schedules and there was no evidence to support a dose response curve for the doses tested. Response rates, defined as having a score within 1.5 standard deviations of the normative mean, were lower for QoL than they were for ADHD symptoms. A subsequent independent metaregression analysis of nine randomized placebo-controlled trials with atomoxetine confirmed the improvement of QoL on the psychosocial summary score of the CHQ-PF50 in atomoxetine treated children and adolescents compared to placebo (Standardised Mean Difference 0.47, 95\% CI 0.250.69) [16]. Both children with ADHD with and without ODD showed significant changes in the psychosocial summary score and on most subscales of the CHQ-PF-50 after 8 weeks of treatment with atomoxetine [52]. These findings were endorsed by a meta-analysis of the results of this and two other studies [13]. However, although the CHQ and symptom-based findings were generally similar, they varied to some extent as a function of group and dose, with some subscales separating from placebo in the $1.8-\mathrm{mg} / \mathrm{kg} /$ day dose group and not the $1.2-\mathrm{mg} / \mathrm{kg} /$ day group. This underscores the importance of looking beyond symptomatic control when evaluating treatments for ADHD.

Brown et al. [15] found only a trend toward a better response to active treatment with atomoxetine than to 
placebo after a 7 week double-blind trial in children with ADHD, while significant improvements were found on both parent and teacher symptom ratings. The effect size relative to placebo was small $(d=0.32)$. With response defined as a total T-score below 60 on the CHQ, significantly more children responded to active medication $(43.8 \%)$ than to placebo $(22.2 \%)$. In a UK study, children were randomized to open label atomoxetine or standard current treatment [60]. Over a 10-week period, overall QoL in children with ADHD improved significantly, as measured with the CHIP-CE total score. A differential effect was found between the study treatments, in favour of atomoxetine over standard "treatment as usual" (mainly methylphenidate). In the atomoxetine group children's mean total CHIP-CE score increased from 23.2 to 38.4 , which is still more than one standard deviation below the norm of 50. After 10 weeks all five parent-reported sub-domains of the CHIP-CE (satisfaction, comfort, risk avoidance, resilience and achievement) were improved. Much less improvement was seen on the patientreported Harter Self Perception Profile, with only one scale (social acceptance domain) showing significant change. Possible reasons for the larger improvement for atomoxetine than methylphenidate suggested by the authors are, a more persistent effect of atomoxetine, with less fluctuations and a possible additional effect on anxiety or tic symptoms [60]. It is also possible that whilst treatment with atomoxetine was optimized during the trial the treatments used in the "treatment as usual" was not.

There is little data on longer term treatment effects on QoL. Perwien et al. [58] report on the changes in the CHQPF-50 over a 10-weeks period and over 24 months open label treatment with atomoxetine. Significant effects were found for the psychosocial scales in the acute treatment phase and these were preserved over the long term, however, no additional improvement in QoL was observed between 10 weeks and 24 months.

\section{Other medications}

Using an unlicensed novel inhibitor of noradrenaline and dopamine reuptake (GW320659), a statistically significant improvement was observed in the psychosocial summary score of the shorter CHQ-PF-28 by DeVeaugh-Geiss et al. [20].

In summary, there is emerging evidence that $\mathrm{QoL}$ improves following effective treatment. This evidence is, however, almost entirely limited to pharmacological treatments and to atomoxetine in particular and almost entirely based on parent report. Several issues still require to be addressed including; the overlap and interactions between improvements QoL and reduction in symptoms and an assessment of the clinical relevance of various degrees of change.

\section{Discussion}

QoL is being increasingly recognized as an important component of a comprehensive assessment of the impact on children and young people of health problems, in general, and ADHD, in particular. However, the QoL concept remains problematic in a number of ways, with multiple competing definitions and measurement approaches [18]. These issues complicate the interpretation of the existing data relating to QoL in ADHD. Notwithstanding these limitations, in the current review we have brought together the existing published data on QoL in ADHD. This allows us to assess the implications of these findings, reflect on issues of interpretation and identify areas for future study.

The current published evidence indicates that QoL is impaired in children with ADHD according to parental report. Across different measures of QoL parents consistently rate the QoL of their children with ADHD as between 1.5 and 2 SD below the appropriate population norms. Furthermore the evidence suggests that QoL impairment increases as the severity of disorder increases, and/or where it is complicated by the presence of comorbidity or psychosocial stressors. The most robust effects are found on the psycho-social and achievement-related measurement scales and those that assess impact on family life. Both inattentive and hyperactive/impulsive ADHD symptoms appear to be equally related to this reduction in QoL. Furthermore, there is evidence to support treatment effects on QoL that to some extent mirror their effects on ADHD symptoms, although with smaller effect sizes. While there is some evidence for child reported reductions in QoL this is less consistent than for parent ratings. There is also fairly consistent evidence that parents and children assess QoL differently, as evidenced by the, modest, correlations between parent and child reports, and that parents tend to rate their children with ADHD as having lower QoL than do the children themselves. While these may in part be related to the measures used (neither of the studies that used the child rated CHQ reported differences between ADHD and healthy children but all four of those that used other scales did) there are several other factors that could account for these findings. Inconsistencies between child and parent ratings of QoL may also reflect age, or sample differences as well as error or true differences. In contrast to children with other psychiatric conditions (e.g., depression), children with ADHD may have an over-optimistic view of their situation. A similar effect has been demonstrated in many studies of self-esteem and self-concept in children with ADHD where it has been hypothesized as being the result of a positive illusory bias [35, 55]. Children with ADHD are hypothesized to overestimate their own abilities and performance in order to protect a positive selfimage [54]. Experimental studies have supported aspects of 
this proposed mechanism $[35,54]$ and it may be important for similar studies to be designed with respect to child reports of QoL in ADHD. Klassen et al. [39] have suggested several other possible reasons for the discrepant findings between child and parent reports of QoL; children may want to conceal their problems; they may ignore them in an attempt to cope with them; they may undergo a process of adaptation to disorder leading to a shift in their internal standards leading to changes in evaluation; they may be making systematic mistakes in rushing through the questionnaires because of their impulsive cognitive style. The finding of larger discrepancies between self- and parent-ratings in children with comorbid ODD/CD and those with additional psychosocial stressors may support the first two hypotheses. This pattern of discrepancy between informants also raises a fundamental conceptual issue given that, in its purest sense, QoL has a strong element of self evaluation. If this view was taken to its logical conclusion the child's view would trump that of the parents. However, at this stage we suggest that a pragmatic approach should involve attempts to develop methods that allow the combining of both proxy and child ratings in order to provide a more comprehensive and integrated assessment [83]. There will, however, need to be more work exploring the psychometric properties of child-report instruments both in general and in ADHD specifically. Future research, including head to head comparisons of parent and child ratings and experimental studies, should also address the differing ways by which children and parents construct the experience and impact of ADHD on the child's QoL. Developmentally sensitive designs that can describe the impact of ADHD on QoL at different ages and the progression of QoL over time would also be very welcome. Large datasets, particularly those derived from community samples, should also be interrogated using data reduction techniques such as factor analysis to identify latent variables. Of particular interest will be studies that have used more than one measure of QoL whereby commonalities between different measures can be identified and possibly translated into new instruments with improved validity and reliability.

Relatively few child studies have compared QoL in ADHD either with QoL in other psychiatric disorders or with chronic physical disorders. Those studies that have been conducted have started to suggest that different disorders may result in different QoL profiles, however, more and larger studies will improve our understanding considerably.

More work is also required to improve our understanding of both the differences and interrelationships between the different levels of analysis that comprise a child's overall functioning (e.g. ADHD symptoms, associated functional impairment and QoL) as these concepts are currently not well delineated either theoretically or on a practical level within the different measurement scales. Different questionnaires contain different mixes of items which tap into all three levels. This means that there is inevitably item-overlap between symptoms rating scales and QoL measures and it then becomes difficult to tease out any independent effects that the disorder or its treatment may be having on symptoms on the one hand and $\mathrm{QoL}$ on the other. This in turn begs the question as to whether an apparent treatment related change as measured by current QoL instruments actually adds anything to our understanding of treatment effects. Whilst we believe that measures of QoL can add considerable colour to the measurement of treatment outcome future research needs to address the contribution of these different elements in characterizing ADHD and its relationship to QoL. A major question to be addressed here would be; does the concept of QoL add any value to our understanding of ADHD over and above the concepts of symptoms and more specific functional impairment? One study [74], explicitly studied aspects of this overlap and reported that the removal of potentially overlapping (symptom) items made little difference to the relationships between mental illness and QoL that they had previously established. There is the potential for similar analyses to be conducted with existing datasets and this may help to provide a more definitive answer to this question. This may suggest ways that the existing measures of QoL could be refined for use with ADHD populations or scored differently when used in this group. This may also result in a clearer delineation of the key characteristics that lay at the core of QoL that are independent of both symptoms and general functional impairment.

Even within the currently limited research into QoL in children with ADHD there is a lack of consistency in terms of the instruments used to measure QoL. These different instruments have been organized into substantially different sub-scale structures and content [18] which has made it very hard to compare QoL across studies and disorders. These differences between the instruments and between researchers regarding their preferred measure are likely to reflect different opinions regarding the best conceptualization of QoL and emphasize the lack of an agreed core QoL paradigm. Sufficient data has not yet been published to perform a meaningful meta-analysis of studies and instruments from which steps could be taken towards the development of a core set of items that could in turn lead to the development of a common instrument. Of course as is frequently the case in psychological research the authors of the current measures of QoL will often have substantial academic and/or financial investment in their own tool and may therefore also be reluctant to engage in a process by which their own measure may be used less frequently in 
future studies. While it is not possible at this stage to recommend one measures as being superior to the others it would be beneficial for studies to be conducted that compared different measures in head to head designs in order that their performance in different groups and different contexts can be described. Studies in children and young people with ADHD that combine questionnaire and interview methods would also be helpful to support the validity of these measures in this group.

Most studies to date have relied on clinic-referred samples, and thus have the potential for referral and Berkson's bias [9]. This has led to a reduced range in outcomes and associated limitations on the power of statistical tests. Further studies are required, to anchor these effects within the wider population.

Most studies have used parental reports both for symptom severity and QoL. This introduces the problem of shared-rater variance and may induce at least two possible sources of bias. This could result in a spurious association between ADHD symptoms and QoL and leaves both measures open to undue influence by parent characteristics: other than the very general data from the ADORE study mentioned above [68], we are unaware of any studies that have investigated the effect of parental mental health on measures of their child's QoL. Future studies should, as a matter of course, take independent ratings of QoL and symptoms. The choice of who should act as the second informant itself raises a number of issues. In the broader field of ADHD, teachers' ratings are often used to address this problem. However, the low correlations found between ratings of QoL by the child or parent and teacher-reported symptoms may be accounted for by the fact that teachers are interested in and observe different maladaptive and adaptive behaviours in the classroom than parents do at home, or that they often only see the children when they are medicated. On the other hand, it is also possible that parents may have exaggerated both symptoms and impact on well-being.

Finally, treatment studies have, to date, been extremely limited in their scope. Studies have focused almost exclusively on one treatment modality (pharmacological) and one molecule (atomoxetine). Stimulants (amfetamines, methylphenidate) are also recommended for the treatment of ADHD [4]. In view of the many measurement issues described above we are not yet at a stage whereby QoL measures can be considered as serious contenders as primary outcome measures in major clinical trials although this may change in the future. One particular psychometric issue that requires clarification in this respect is clarification of what constitutes a clinically meaning change for these measures. We do, however, strongly recommend that those designing and conducting future clinical trials, both pharmacological and psychosocial, should include measures of QoL as secondary outcome measures. Although we are aware of several ongoing RCTs of stimulant medication that are using QoL measures at present no systematic published data from RCTs on the impact of methylphenidate on QoL in ADHD, only one RCT of amfetamines and none with psychosocial treatment, this needs to be addressed urgently. It should also be noted that the total number of individual children that have had their QoL measured as a part of the atomoxetine development program is less than it may initially appear to the casual reader. Several of the meta analyses have included data from the same trials and all of the children in the long term open label follow-up study described by Perwin et al. [58] were enrolled into the long term study following their having completed participation in an RCT and are therefore likely to be included in at least one other publication. The lack of systematic studies of psychological therapies either on their own or in multimodal combinations with medication is a further omission in our understanding of the impact of treatment on QoL.

Studies have, on the whole, had relatively short followup periods and it may be the case that some aspects of QoL will take more time for change and would therefore not be seen in these short-term clinical trials. However, Perwien et al.'s longer term study [58] failed to show any additional improvement in QoL after the acute treatment period.

There has been no systematic analysis of the extent to which changes in QoL are mediated by symptom changes, changes in functional impairment or other factors. This task is complicated enormously by the fact that the concept of QoL appears to be somewhat confounded in current scales with ADHD symptoms and functional impairment.

Although it is likely that QoL, in relation to medication response, will probably be influenced by a mixture of positive treatment responses and side effects the role of adverse events, in determining QoL following treatment, has not yet been reported in any of the published studies.

Most studies have either had strict inclusion and exclusion criteria that have not allowed the recruitment of those with comorbid disorders or have failed to control for comorbid disorders such as ODD, anxiety and depression, either at baseline or when assessing the responsiveness of QoL to treatment, even though it is recognized that several subscales of the QoL measures contain items on behaviour problems, depressive symptoms and anxiety. At the same time, it seems clear that some of the QoL effects demonstrated in ADHD are clearly distinct from ADHD symptoms, e.g. peer and family relation impact.

The ADORE study [61] collected naturalistic observational data on ADHD symptoms, impairment, comorbidity and QoL over a 2 years period on a large group of children and young people with ADHD who were receiving a wide range of pharmacological and non-pharmacological 
treatments. Data from the longitudinal portion of this study has been submitted for publication and will help to address many of these issues. However, it is also essential that further well designed clinical trials which utilise both child and parent proxy completed QoL measures are conducted and in particular head-to-head studies of different treatment packages with a broad range of outcomes over extended periods of time, with multiple testing points are required. These studies should be designed in such a way to allow the exploration of the natural history of changes in QoL following treatment as well as the mediating effects of symptom reductions and other factors on longer term changes in well-being.

In addition to acting as an outcome measure QoL measures could be helpful within the clinical setting as an indicator of clinical need and assist the clinician in identifying areas of life that are particularly difficult for a child in order that appropriate support can be engaged. ADHD impacts on many aspects of life and although clinicians now have much more information regarding the best ways to reduce ADHD symptoms it is also important for us to always be alert to the associated difficulties faced by these children and to consider how best we can improve their lives.

In summary, published studies to a degree support an impact of ADHD on QoL, which is at least as great as seen for many physical disorders. These effects are greatest, and most consistent, with parent ratings than child-self ratings. Future research needs to distinguish QoL effects from those related only to symptoms and functional impairment; study the differences between child and parent perceptions of ADHD and its impact; identify common elements across the multiple measures currently in use; use population as well clinical samples; include independent ratings of QoL and ADHD symptoms; study the effects of a broader range of treatments in a way that allows the assessment of mediating and moderating factors.

Acknowledgments This paper is derived from a work group meeting of the European ADHD Guidelines Group which was supported by an unrestricted educational grant (costs of the meeting only) from: Elli Lilly, Janssen-Cilag, and Novartis \& Shire.

\section{References}

1. American Psychiatric Association (2000) Diagnostic and Statistical Manual of Mental Disorders (DSM-IV TR). The Press, Washington (DC)

2. August GJ, Braswell L, Thuras P (1998) Diagnostic stability of ADHD in a community sample of school-aged children screened for disruptive behavior. J Abnorm Child Psychol 26:345-356

3. Bagwell CL, Molina BS, Pelham WE Jr, Hoza B (2001) Attention-deficit hyperactivity disorder and problems in peer relations: predictions from childhood to adolescence. J Am Acad Child Adolesc Psychiatry 40:1285-1292
4. Banaschewski T, Coghill D, Santosh P, Zuddas A, Asherson P, Buitelaar J, Danckaerts M, Dopfner M, Faraone SV, Rothenberger A, Sergeant J, Steinhausen HC, Sonuga-Barke EJ, Taylor E (2006) Long-acting medications for the hyperkinetic disorders. A systematic review and European treatment guideline. Eur Child Adolesc Psychiatry 15:476-495

5. Barkley RA, Fischer M, Smallish L, Fletcher K (2006) Young adult outcome of hyperactive children: adaptive functioning in major life activities. J Am Acad Child Adolesc Psychiatry 45:192-202

6. Barkley RA, McMurray MB, Edelbrock CS, Robbins K (1990) Side effects of methylphenidate in children with attention deficit hyperactivity disorder: a systemic, placebo-controlled evaluation. Pediatrics 86:184-192

7. Bastiaansen D, Koot HM, Ferdinand RF, Verhulst FC (2004) Quality of life in children with psychiatric disorders: self-, parent, and clinician report. J Am Acad Child Adolesc Psychiatry 43(2):221-230

8. Bastiaansen D, Koot HM, Ferdinand RF (2005) Psychopathology in children: improvement of quality of life without psychiatric symptom reduction? Eur Child Adoles Psychiatry 14(7):364-370

9. Berkson J (1946) Limitations of the application of the fourfold table analysis to hospital data. Biometrics 2:47-53

10. Bibace R, Walsh ME (1980) Development of children's concepts of illness. Pediatrics 66:912-917

11. Biederman J, Faraone SV, Lapey K (1992) Comorbidity of diagnosis in attention-deficit hyperactivity disorder. Child Adolesc Psychiatric Clin N A 1:335-360

12. Biederman J, Monuteaux MC, Mick E, Spencer T, Wilens TE, Silva JM, Snyder LE, Faraone SV (2006) Young adult outcome of attention deficit hyperactivity disorder: a controlled 10-year follow-up study. Psychol Med 36:167-179

13. Biederman J, Spencer TJ, Newcorn JH, Gao H, Milton DR, Feldman PD, Witte MM (2007) Effect of comorbid symptoms of oppositional defiant disorder on responses to atomoxetine in children with ADHD: a meta-analysis of controlled clinical trial data. Psychopharmacology (Berl) 190:31-41

14. Biederman J, Wilens TE, Mick E, Faraone SV, Spencer T (1998) Does attention-deficit hyperactivity disorder impact the developmental course of drug and alcohol abuse and dependence? Biol Psychiatry 44:269-273

15. Brown RT, Perwien A, Faries DE, Kratochvil CJ, Vaughan BS (2006) Atomoxetine in the management of children with ADHD: effects on quality of life and school functioning. Clin Pediatr (Phila) 45:819-827

16. Cheng JY, Chen RY, Ko JS, Ng EM (2007) Efficacy and safety of atomoxetine for attention-deficit/hyperactivity disorder in children and adolescents-meta-analysis and meta-regression analysis. Psychopharmacology (Berl) 194:197-209

17. Christie MJ, French D, Sowden A, West A (1993) Development of child-centered disease-specific questionnaires for living with asthma. Psychosom Med 55:541-548

18. Coghill D, Danckaerts $M$, Sonuga-Barke E, Sergeant $J$, the ADHD European Guidelines Group (2008) Practitioner review: quality of life in child mental health-conceptual challenges and practical choices. J Child Psychol Psychiatry 50(5):544-561

19. Coghill D, Spender Q, Barton J, Hollis C, Yuen C, Cleemput L, Annemans L (2004) Measuring quality of life in children with attention-deficit-hyperactivity disorder in the UK. Poster presented at International Association for Child and Adolescent Psychiatry and Allied Professions, Berlin, Germany

20. DeVeaugh-Geiss J, Conners CK, Sarkis EH, Winner PK, Ginsberg LD, Hemphill JM, Laurenza A, Barrows CE, Webster CJ, Stotka CJ, Asgharnejad M (2002) GW320659 for the treatment of attention-deficit/hyperactivity disorder in children. J Am Acad Child Adolesc Psychiatry 41:914-920 
21. Dolan P (2000) The measurement of health-related quality of life for use in resource allocation decisions in health care. In: Culyer AJ, Newhouse JP (eds) Handbook of Health Economics. Elsevier, North-Holland, pp 1723-1760

22. Edwards TC, Huebner CE, Connell FA, Patrick DL (2002) Adolescent quality of life, part I: conceptual and measurement model. J Adolesc 25:275-286

23. Eiser C, Cotter I, Oades P, Seamark D, Smith R (1999) Healthrelated quality-of-life measures for children. Int J Cancer Suppl 12:87-90

24. Eiser C, Morse R (2001) Quality-of-life measures in chronic diseases of childhood. Health Technol Assess 5:1-157

25. Erhardt D, Hinshaw SP (1994) Initial sociometric impressions of attention-deficit hyperactivity disorder and comparison boys: predictions from social behaviors and from nonbehavioral variables. J Consult Clin Psychol 62:833-842

26. Escobar R, Soutullo CA, Hervas A, Gastaminza X, Polavieja P, Gilaberte I (2005) Worse quality of life for children with newly diagnosed attention-deficit/hyperactivity disorder, compared with asthmatic and healthy children. [erratum appears in Pediatrics. 2005 Nov;116(5):1266]. Pediatrics 116(3):e364-e369

27. EuroQol Group (1990) EuroQol: a new facility for the measurement of health-related quality of life. Health Policy 16:199208

28. Flapper BC, Schoemaker MM, Flapper Boudien CT, Schoemaker Marina M (2008) Effects of methylphenidate on quality of life in children with both developmental coordination disorder and ADHD. Develop Med Child Neurol 50:294-299

29. Graetz BW, Sawyer MG, Hazell PL, Arney F, Baghurst P (2001) Validity of DSM-IVADHD subtypes in a nationally representative sample of Australian children and adolescents. J Am Acad Child Adolesc Psychiatry 40:1410-1417

30. Graham J, Coghill D (2008) Adverse effects of pharmacotherapies for attention-deficit hyperactivity disorder: epidemiology, prevention and management. CNS Drugs 22:213-237

31. Gringras P, Santosh P, Baird G (2006) Development of an Internet-based real-time system for monitoring pharmacological interventions in children with neurodevelopmental and neuropsychiatric disorders. Child Care Health Dev 32(5):591-600

32. Hakkaart-van Roijen L, Zwirs BWC, Bouwmans C, Tan SS, Schulpen TWJ, Vlasveld L, Buitelaar JK (2007) Societal costs and quality of life of children suffering from attention deficient hyperactivity disorder (ADHD). Eur Child Adolesc Psychiatry 16(5):316-326

33. Hampel P, Desman C (2006) Coping and quality of life among children and adolescents with attention deficit/hyperactivity disorder. Prax Kinderpsychol Kinderpsychiatr 55:425-443

34. Harter S, Pike R (1984) The pictorial scale of perceived competence and social acceptance for young children. Child Dev 55:1969-1982

35. Hoza B, Pelham WE Jr, Dobbs J, Owens JS, Pillow DR (2002) Do boys with attention-deficit/hyperactivity disorder have positive illusory self-concepts? J Abnorm Psychol 111:268-278

36. Juniper EF, Guyatt GH, Feeny DH, Griffith LE, Ferrie PJ (1997) Minimum skills required by children to complete health-related quality of life instruments for asthma: comparison of measurement properties. Eur Respir J 10:2285-2294

37. Klassen AF (2005) Quality of Life of children with attention deficit hyperactivity disorder. Expert Rev Pharmacoecon Outcomes Res 5:95-103

38. Klassen AF, Miller A, Fine S (2004) Health-related quality of life in children and adolescents who have a diagnosis of attentiondeficit/hyperactivity disorder. Pediatrics 114(5):e541-e547

39. Klassen AF, Miller A, Fine S (2006) Agreement between parent and child report of quality of life in children with attention- deficit/hyperactivity disorder. [References]. Child Care Health Dev 32:397-406

40. Kolsteren MM, Koopman HM, Schalekamp G, Mearin ML (2001) Health-related quality of life in children with celiac disease. J Pediatr 138:593-595

41. Landgraf JM, Abetz LN (1997) Functional status and well-being of children representing 3 cultural groups: initial self reports using the CHQ-CF87. Psychol Health 12:839-854

42. Landgraf JM, Abetz LN, Ware JE (1999) The CHQ users manual. Boston, Health Act, MA

43. Landgraf JM, Rich M, Rappaport L (2002) Measuring quality of life in children with attention-deficit/hyperactivity disorder and their families: development and evaluation of a new tool. Arch Pediatr Adolesc Med 156:384-391

44. Leidy NK, Rich M, Geneste B (1999) Recomendations for evaluating the validity of life claims for labeling and promotion. Value Health 2:113-127

45. Matza LS, Rentz AM, Secnik K, Swensen AR, Revicki DA, Michelson D, Spencer T, Newcorn JH, Kratochvil CJ (2004) The link between health-related quality of life and clinical symptoms among children with attention-deficit hyperactivity disorder. J Dev Behav Pediatr 25:166-174

46. Matza LS, Secnik K, Mannix S, Sallee FR (2005) Parent-proxy EQ-5D ratings of children with attention-deficit hyperactivity disorder in the US and the UK. Pharmacoeconomics 23(8):777790

47. Matza LS, Secnik K, Rentz AM, Mannix S, Sallee FR, Gilbert D, Revicki DA (2005) Assessment of health state utilities for attention-deficit/hyperactivity disorder in children using parent proxy report. Qual Life Res 14:735-747

48. Matza LS, Swensen AR, Flood EM, Secnik K, Leidy NK (2004) Assessment of health-related quality of life in children: a review of conceptual, methodological, and regulatory issues. Value Health 7:79-92

49. Mize J, Ladd GW (1988) Predicting preschoolers peer behaviour and status from their interpersonal strategies - a comparison of verbal and enactive responses to hypothetical social situations. Develop Psychol 24:782-788

50. Moss MS, Hoffman CJ, Mossey J, Rovine M (2007) Changes over 4 years in health, quality of life, mental health, and valuation of life. J Aging Health 19:1025-1044

51. National Institute for Mental Health (1985) Clinical global impressions. Psychopharmacol Bull 21:839-843

52. Newcorn JH, Spencer TJ, Biederman J, Milton DR, Michelson D (2005) Atomoxetine treatment in children and adolescents with attention-deficit/hyperactivity disorder and comorbid oppositional defiant disorder. J Am Acad Child Adolesc Psychiatry 44:240-248

53. Norman GR, Sloan JA, Wyrwich KW (2003) Interpretation of changes in health-related quality of life: the remarkable universality of half a standard deviation. Med Care 41:582-592

54. Ohan JL, Johnston C (2002) Are the performance overestimates given by boys with ADHD self-protective? J Clin Child Adolesc Psychol 31:230-241

55. Owens JS, Hoza B (2003) The role of inattention and hyperactivity/impulsivity in the positive illusory bias. J Consult Clin Psychol 71:680-691

56. Patrick DL, Edwards TC, Topolski TD (2002) Adolescent quality of life, part II: initial validation of a new instrument. J Adolesc 25(3):287-300

57. Perwien AR, Faries DE, Kratochvil CJ, Sumner CR, Kelsey DK, Allen AJ (2004) Improvement in health-related quality of life in children with ADHD: an analysis of placebo controlled studies of atomoxetine. [see comment]. J Develop Behav Pediatrics 25(4):264-271 
58. Perwien AR, Kratochvil CJ, Faries DE, Vaughan BS, Spencer T, Brown RT (2006) Atomoxetine treatment in children and adolescents with attention-deficit hyperactivity disorder: what are the long-term health-related quality-of-life outcomes? J Child Adolesc Psychopharmacol 16(6):713-724

59. Pongwilairat K, Louthrenoo O, Charnsil C, Witoonchart C (2005) Quality of life of children with attention-deficit/hyper activity disorder. J Med Assoc Thai 88(8):1062-1066

60. Prasad S, Harpin V, Poole L, Zeitlin H, Jamdar S, Puvanendran K (2007) A multi-centre, randomised, open-label study of atomoxetine compared with standard current therapy in UK children and adolescents with attention-deficit/hyperactivity disorder (ADHD). Curr Med Res Opin 23:379-394

61. Preuss U, Ralston SJ, Baldursson G, Falissard B, Lorenzo MJ, Rodrigues PR, Vlasveld L, Coghill D (2006) Study design, baseline patient characteristics and intervention in a cross-cultural framework: results from the ADORE study. Eur Child Adolesc Psychiatry 15(Suppl 1):i4-i14

62. Ravens-Sieberer U, Bullinger M (1998) Assessing health-related quality of life in chronically ill children with the German KINDL: first psychometric and content analytical results. Qual Life Res 7:399-407

63. Rebok G, Riley A, Forrest C, Starfield B, Green B, Robertson J, Tambor E (2001) Elementary school-aged children's reports of their health: a cognitive interviewing study. Qual Life Res 10:5970

64. Rentz AM, Matza LS, Secnik K, Swensen A, Revicki DA (2005) Psychometric validation of the child health questionnaire (CHQ) in a sample of children and adolescents with attention-deficit/ hyperactivity disorder. Qual Life Res 14(3):719-734

65. Riley AW, Coghill D, Forrest CB, Lorenzo MJ, Ralston SJ, Spiel G (2006) Validity of the health-related quality of life assessment in the ADORE study: parent report form of the CHIP-Child Edition. Eur Child Adolesc Psychiatry 15(Suppl 1):i63-i71

66. Riley AW, Forrest CB, Rebok GW, Starfield B, Green BF, Robertson JA, Friello P (2004) The child report form of the CHIP-Child Edition: reliability and validity. Med Care 42:221-231

67. Riley AW, Forrest CB, Starfield B, Rebok G, Robertson JA, Green BF (2004) The parent report form of the CHIP-Child Edition: reliability and validity. Med Care 42:210-220

68. Riley AW, Spiel G, Coghill D, Dopfner M, Falissard B, Lorenzo MJ, Preuss U, Ralston SJ (2006) Factors related to HealthRelated Quality of Life (HRQoL) among children with ADHD in Europe at entry into treatment. Eur.Child Adolesc.Psychiatry 15(Suppl 1):i38-i45

69. Rimmer M, Campbell C, Coghill D (2007) ADHD: the Impact on Parent's and Children's Quality of Life. Boston, American Academy of Child and Adolescent Psychiatry Annual Meeting

70. Rudnick A (2001) The impact of coping on the relation between symptoms and quality of life in schizophrenia. Psychiatry 64:304-308

71. Sallee FR, Ambrosini PJ, Lopez FA, Shi L, Michaels MA (2004) Health-related quality of life and treatment satisfaction and preference in a community assessment study of extended-release mixed amphetamine salts for children with attention-deficit/ hyperactivity disorder. J Outcomes Res 2:7-49

72. Satterfield J, Swanson J, Schell A, Lee F (1994) Prediction of antisocial behavior in attention-deficit hyperactivity disorder boys from aggression/defiance scores. J Am Acad Child Adolesc Psychiatry 33:185-190

73. Satterfield JH, Schell A (1997) A prospective study of hyperactive boys with conduct problems and normal boys: adolescent and adult criminality. J Am Acad Child Adolesc Psychiatry 36:17261735

74. Sawyer MG, Arney F, Baghurst P, Clark JJ, Graetz BW, Kosky RJ, Nurcombe B, Patton GC, Prior MR, Raphael B, Rey J,
Whaites LC, Zubrick SR (2000) The Mental Health of Young People in Australia. Adelaide, Mental Health and Special Programs Branch, Commonwealth Department of Health and Aged Care

75. Sawyer MG, Whaites L, Rey JM, Hazell PL, Graetz BW, Baghurst P (2002) Health-related quality of life of children and adolescents with mental disorders. J Am Acad Child Adolesc Psychiatry 41(5):530-537

76. Secnik K, Matza LS, Cottrell S, Edgell E, Tilden D, Mannix S (2005) Health state utilities for childhood attention-deficit/ hyperactivity disorder based on parent preferences in the United Kingdom. Med Decis Making 25:56-70

77. Shaffer D, Gould MS, Brasic J, Ambrosini P, Fisher P, Bird H, Aluwahlia S (1983) A children's global assessment scale (CGAS). Arch Gen Psychiatry 40:1228-1231

78. Solans BS, Pane S, Estrada M-D, Serra-Sutton S, Berra S, Herdman M, Alonso J, Rajmil L (2008) Health-related quality of life measurement in children and adolescents: a systematic review of generic and disease-specific instruments. Value Health 11:742-764

79. Spitzer RL, Kroenke K, Linzer M, Hahn SR, Williams JB, deGruy FVIII, Brody D, Davies M (1995) Health-related quality of life in primary care patients with mental disorders. Results from the PRIME-MD 1000 Study. JAMA 274:1511-1517

80. Taylor E, Dopfner M, Sergeant J, Asherson P, Banaschewski T, Buitelaar J, Coghill D, Danckaerts M, Rothenberger A, SonugaBarke E, Steinhausen HC, Zuddas A (2004) European clinical guidelines for hyperkinetic disorder-first upgrade. Eur Child Adolesc Psychiatry 13(Suppl 1):I7-I30

81. The ADORE Study Group. (2005) European ADHD Observational Study (ADORE): Longitudinal Results (baseline3 months). Toronto, American Academy of Child and Adolescent Psychiatry Annual Meeting

82. Topolski TD, Edwards TC, Patrick DL, Varley P, Way ME, Buesching DP (2004) Quality of life of adolescent males with attention-deficit hyperactivity disorder. J Atten Disord 7:163-173

83. Varni JW, Burwinkle TM (2006) The PedsQL as a patientreported outcome in children and adolescents with AttentionDeficit/Hyperactivity Disorder: a population-based study. Health Qual Life Outcomes 4:26

84. Varni JW, Burwinkle CA, Limbers TM, Szer IS (2007) The PedsQL as a patient-reported outcome in children and adolescents with fibromyalgia: an analysis of OMERACT domains. Health Qual Life Outcomes 5:9

85. Varni JW, Seid M, Kurtin PS (2001) PedsQL 4.0: reliability and validity of the Pediatric Quality of Life Inventory version 4.0 generic core scales in healthy and patient populations. Med Care 39:800-812

86. Varni JW, Seid M, Rode CA (1999) The PedsQL: measurement model for the pediatric quality of life inventory. Med Care 37:126-139

87. Vogels T, Verrips GH, Verloove-Vanhorick SP, Fekkes M, Kamphuis RP, Koopman HM, Theunissen NC, Wit JM (1998) Measuring health-related quality of life in children: the development of the TACQOL parent form. Qual Life Res 7:457-465

88. Wehmeier PM, Dittmann RW, Schacht A, Minarzyk A, Lehmann M, Sevecke K, Lehmkuhl G, Wehmeier PM, Dittmann RW, Schacht A, Minarzyk A, Lehmann M, Sevecke K, Lehmkuhl G (2007) Effectiveness of atomoxetine and quality of life in children with attention-deficit/hyperactivity disorder as perceived by patients, parents, and physicians in an open-label study. J Child Adolesc Psychopharmacol 17:813-830

89. Wehmeier PM, Schacht A, Dittmann RW, Dopfner M (2008) Global impression of perceived difficulties in children and adolescents with attention-deficit/hyperactivity disorder: reliability and validity of a new instrument assessing perceived difficulties 
from a patient, parent and physician perspective over the day. Child Adolesc Psychiatry Ment Health 2:10

90. Weiss MD, Brooks BL (2007) Clinical normative data for the Weiss Functional Impairment Rating Scale. American Academy of Child and Adolescent Psychiatry Annual Meeting, Boston

91. WHOQOL (1995) World Health Organisation Quality of Life Assessment (WHOQOL): position paper from the World Health Organisation. Soc Sci Med 41:1403-1409

92. Wigal SB, Wigal TL, McGough JM, Kollins SH, Biederman JB, Posner KL (2005) A Laboratory School Comparison of Mixed Amphetamine Salts Extended Release (Adderall $\mathrm{XR}^{\circledR}$ ) and Atomoxetine $\left(\right.$ Strattera $\left.{ }^{\circledR}\right)$ in school-aged children with attention deficit/hyperactivity disorder. J Atten Disord 9:275-289

93. Willcutt EG, Doyle AE, Nigg JT, Faraone SV, Pennington BF (2005) Validity of the executive function theory of attention- deficit/hyperactivity disorder: a meta-analytic review. Biol Psychiatry $57: 1336-1346$

94. Wilson JM, Marcotte AC (1996) Psychosocial adjustment and educational outcome in adolescents with a childhood diagnosis of attention deficit disorder. J Am Acad Child Adolesc Psychiatry 35:579-587

95. World Health Organisation (1947) World Health Organisation Constitution. World Health Organisation, Geneva

96. World Health Organisation (1992) International Classification of Diseases (ICD-10). Geneva, WHO

97. Yang P, Hsu HY, Chiou SS, Chao MC (2007) Health-related quality of life in methylphenidate-treated children with attentiondeficit-hyperactivity disorder: results from a Taiwanese sample. Aust N Z J Psychiatry 41:998-1004 